\title{
PENGARUH PERLAKUAN AWAL TERHADAP DAYA REKAT DAN KEKUATAN LAPISAN PADA PROSES PENGECATAN SERBUK
}

\section{The Influence of Pre-Treatment to Sticky Power and Layer Strength on Powder Coating Process}

\author{
Tri Mulyanto ${ }^{1 *}$, Supriyono ${ }^{1}$ dan Satya Parama Arta ${ }^{1}$ \\ ${ }^{1}$ Universitas Gunadarma, Jl. Margonda Raya no. 100, Indonesia
}

Informasi artikel

Diterima: $28 / 12 / 2019$

Direvisi : 05/01/2020

Disetujui: 07/01/2020

\begin{abstract}
Abstrak
Pengecatan serbuk adalah metode pelapisan logam yang merupakan proses akhir dilakukan untuk memperindah atau melindungi logam dari serangan korosi. Proses menggunakan bahan dari resin yang kering untuk mencapai daya rekat dan kekuatan serta ketahan korosi yang maksimal. Sebelum dilakukan pelapisan dilakukan proses pelakuan awal untuk proses pembersihaan permukaan material yang bertujuan untuk meningkatkan gaya adhesi antara serbuk pelapis dengan material logam yang dilapisi. Perlakuan awal memegang peranan yang sangat penting dalam menentukan kualitas pelapisan yang dihasilkan. Penelitian untuk mengetahui pengaruh perlakuan awal terhadap daya rekat dan kekuatan lapisan pada proses pengecatan serbuk. Perlakuan awal yang dilakukan adalah amplas grit 150, penembakan pasir dan cairan kimia phosphat. Hasil pengujian adhesion/kelekatan didapatkan $0 \%$ terkelupas. Hasil pengujian ketahanan yang terbaik didapatkan dengan perlakuan awal penembakan pasir dan cairan kimia phosphating dengan tidak ada retak pada hasil lapisan. Hasil pengujian daya rekat yang terbaik didapat dengan perlakuan awal phosphating dengan nilai tarik ratarata $4.3 \mathrm{MPa}$.
\end{abstract}

Kata Kunci: daya rekat, kekuatan lapisan, pengecatan serbuk, perlakuan awal.

\begin{abstract}
Powder coating is a metal coating method which is the final process carried out to beautify or protect the metal from corrosion. The process uses materials from dried resins to achieve sticky power and Layer strength and corrosion resistance maximum. Before the coating is carried out the pretreatment process for the surface cleaning process of the material aims to improve the adhesion force between the coating powder with coated metal material. The pre-treatment plays a very important role in determining the quality of the resulting coating. Research to determine the effect of pretreatment on the adhesion and strength of the coating on the powder painting process. The initial treatment taken was sandpaper grit 150, sand shooting and phosphate chemical liquid. . The adhesion / viscosity test results found $0 \%$ peeling off. The impact test results were obtained by pre-treatment of sand and phosphating chemical liquids with no cracking in the coating results. The best adhesive test results are obtained by pre-treating phosphating with an average tensile value of $4.3 \mathrm{MPa}$.
\end{abstract}

Keywords: sticky power, layer strength, powder coating, pre-treatment. 


\section{PENDAHULUAN}

Aplikasi utama pengecatan serbuk adalah untuk meningkatkan sifat-sifat seperti ke-tahanan gores, ketahanan korosi dan lainlain pada permukaan berbagai macam produk. Dengan demikian dalam semua aplikasi kualitas lapisan yang terbentuk selama pelapisan bubuk sangat penting. Ketebalan lapisan adalah parameter penting karena endapan berlebih bubuk akan meningkatkan lapisan material dan ketebalan rendah akan menyebabkan paparan ke atmosfer dan akibatnya korosi, berkarat (Karidkar, 2016).

Aktivitas ini dilakukan untuk meningkatkan pendapatan perusahaan dengan cara memanfaatkan perkembangan teknologi yang ada. Salah satu teknologi yang digunakan adalah untuk meningkatkan ketahanan logam terhadap kerusakan struktur agar dapat memperpanjang umur logam. Komponenkomponen yang terbuat dari logam dapat dilapisi dengan lapisan pelindung, proses ini penting dilakukan agar tidak cepat terserang korosi selain untuk keindahan penampilan. Korosi adalah kehancuran atau kerusakan material karena reaksi dengan lingkungannya (Fontana, 1986). Korosi dapat terjadi disebabkan terjadinya reaksi logam tersebut dengan unsur bukan logam di lingkungan kerja komponen. Korosi ini sendiri bisa mengakibatkan menurunnya kualitas dari baja tersebut sehingga mengakibatkan logam tersebut menjadi cepat lemah dan rusak (Yudha et al. 2015 dan Febi, 2017).

Pencegahan dan perlindungan terhadap korosidapat dilakukan dengan cara pelapisan, yaitu dengan menggunakan bahan cat cair yang biasa dilakukan pada cat konvensional atau dengan pelapisan dengan sistem powder coating. Powder coating merupakan salah satu sistem pengecatan yang berkembang pesat saat ini dengan tujuan untuk memperbaiki sifat logam agar tahan korosi dan dapat memperindah penampilan permukaan logam. Powder coating adalah proses pengecatan kering dimana bahan resin, pigmen dan lain lain dihaluskan serta diberikan muatan elektro-statis yang kemudian disemprotkan ke material yang akan dilapisi. Untuk mencapai daya rekat yang maksimal maka sebelum dilakukan pelapisan, material yang akan dilapisi dibersihkan dan diberikan pre-treatment tertentu (Carolus et al, 2016 dan Febi, 2017).
Pengecatan serbuk (powder coating) memiliki beberapa kelebihan (Ramdhoni, 2015), yaitu :

a. Serbuk pelapis cat dapat menghasilkan lapisan lebih tebal dari pada lapisan cair konvensional.

b. Serbuk pelapisan overspray dapat didaur ulang dan oleh karena itu mungkin untuk mencapai hampir $100 \%$ dari penggunaan lapisan.

c. Pelapisan powder coating menghasilkan limbah yang kurang berbahaya dibandigkan pelapisan menggunakan cat cair konvensional.

d. Benda kerja yang dilapisi dengan serbuk cat powder coating umumnya memiliki penampilan sedikit berbeda antara permukaan horisontal dan vertikal dibandingakan benda kerja dilapisi cat cairan.

e. Berbagai efek khusus yang dapat mudah ditambahkan dengan menggunakan pelapisan powder coating, yang sulit didapat dengan proses pelapisan yang lainnya.

Pada proses powder coating selain dari bahan cat terdapat berbagai faktor yang dapat mempengaruhi kualitas pelapisan. Faktor tersebut dapat berupa perlakuan awal proses lapisan, proses lapisannya, dan pengerjaan akhir atau pengeringan cat itu sendiri (Ramdhoni, 2015). Keberhasilan dari proses coating sangat tergantung pada proses surface preparation, dimana proses ini akan mempengaruhi kekuatan adhesi dari material (Hudson, 1982). Salah satu teknik dari surface preparation yang umum digunakan dalam dunia industri adalah blasting. Proses ini merupakan pembersihan permukaan dengan cara menembakan material abrasif ke suatu permukaan material dengan tekanan tinggi sehingga menimbulkan gesekan/tumbukan. Permukaan material tersebut akan menjadi bersih dan kasar. Pemilihan dan penggunaan material abrasif yang tepat akan menambah daya lekat cat.

Tujuan penelitian ini adalah mengetahui daya rekat (sticky power) dan kekuatan lapisan (layer strength) pada hasil proses pengecatan serbuk yang mendapatkan perlakuan awal (pretreatment) berbeda yaitu: cairan kimia asam phospat, sand blasting (glass beads) dan Power Tool (amplas). Cat serbuk yang digunakan corrocoat $M X$ series 8 (C001) dan sebagai sampel uji digunakan mild steel A36. 


\section{METODOLOGI}

Penelitian menggunakan tiga macam perlakuan awal. Dalam upaya melakukan penelitian disusunlah suatu langkah-langkah penelitian. Secara garis besar langkah penelitian dijelaskan pada diagram alir gambar 1 berikut.

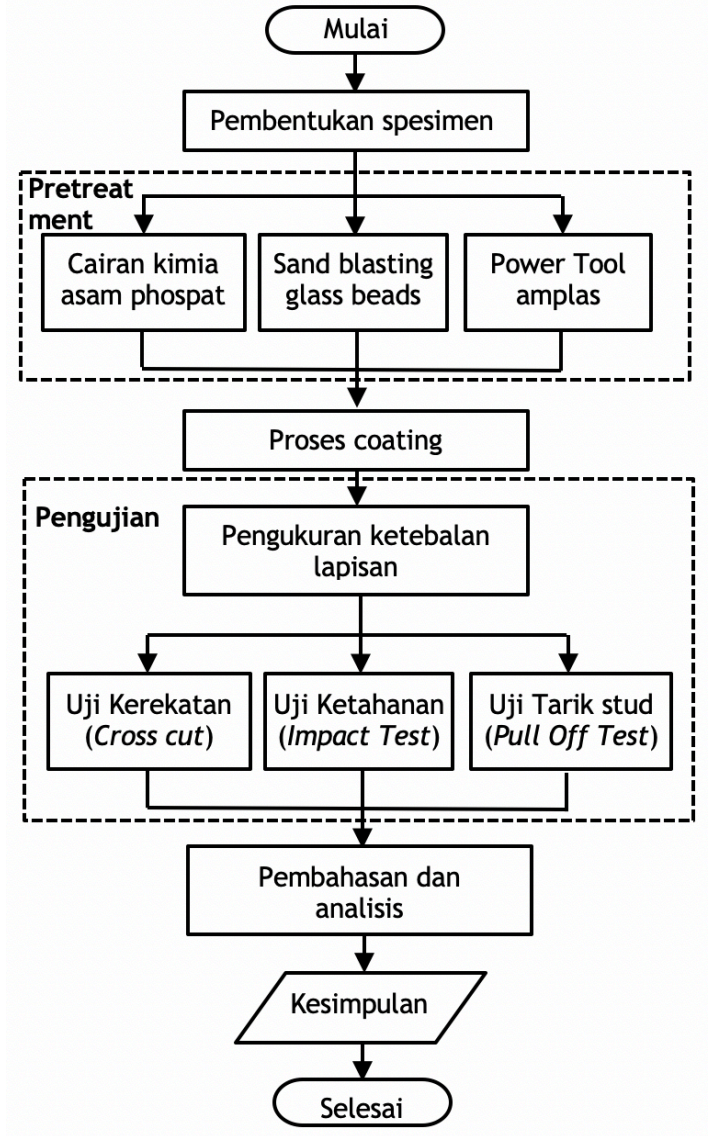

Gambar 1 Diagram alir penelitian

\section{Spesimen Uji}

Sampel uji yang digunakan mild steel A36 memiliki ukuran yaitu: 100×50x4 mm dengan jumlah 18 buah spesimen untuk Cross cut test serta Impact Test dan ukuran 100x100x4 mm dengan jumlah 9 buah specimen untuk Pull Off Test.

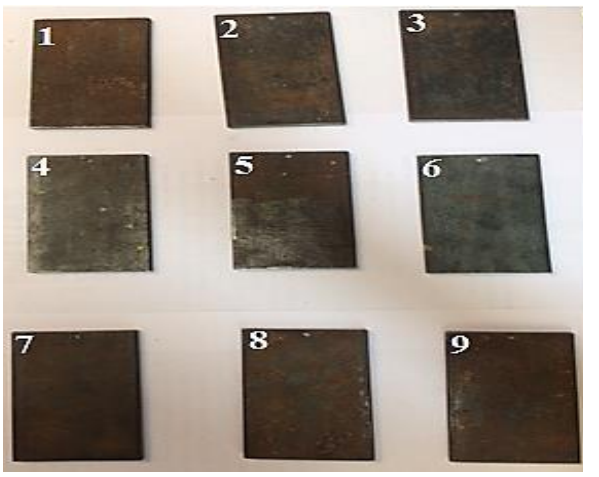

Gambar 2 Spesimen uji

\section{Perlakuan awal}

Proses perlakuan awal (pre-treatment) bertujuan untuk menghilangkan kotoran seperti minyak, karat dan pengotor lainya agar didapat hasil coating yang baik (Rakhmadi, 2008). Dalam penelitian ini diambil 3 (tiga) cara perlakuan awal, yaitu :

a. Phospating.

Proses perlakuan awal terhadap logam yang dilakukan dengan cara direndam selama 20 menit didalam zat cair kimia asam phosphat $\left(\mathrm{H}_{3} \mathrm{PO}_{4}\right)$, kemudian dicuci dengan air yang digunakan membersihkan keseluruhan permukaan logam.

b. Sandblasting.

Proses perlakuan awal terhadap logam dengan menggunakan glass beads yang bertekan 4 bar untuk membersihkan permukaan dari karat, minyak dan pengotor lainnya.

c. Power tool.

Proses perlakuan awal terhadap logam yang dioperasikan tidak dengan tenaga manusia namun dioperasikan dengan menggunakan listrik, power tool yang digunakan untuk membersihkan permukaannya adalah amplas grit 150 .

\section{Proses Coating}

Pada proses coating yang dilakukan pertama yaitu menyiapkan sampel uji yang telah dilakukan proses perlakuan awal (pretreatment). Setelah itu masing-masing sample digantungkan pada media yang telah disiapkan. Langkah berikutnya yaitu siapkan bubuk cat corro-coat MX series 8 (C001). Pemilihan jenis bubuk cat ini karena memiliki keunggulan seperti tahan panas, stabilitas warna. Setelah bubuk cat siap maka bubuk cat dimasukan kedalam tabung spray gun lalu disemprotkan kesampel uji tersebut sebanyak 2 layer dengan jarak pengecatan yang ideal sebesar $25-30 \mathrm{~cm}$.

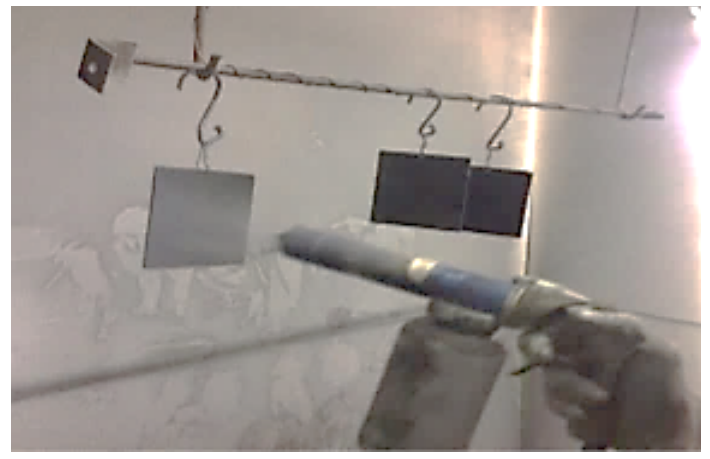

Gambar 3 Proses coating 


\section{Pengujian dan Pengukuran}

Pengujian yang digunakan pada hasil pelapisan antara lain:

a. Pengukuran ketebalan lapisan cat. Pengukuran ketebalan lapisan (coating thickness gauge) dilakukan untuk dapat mengidentifikasi standar yang dapat digunakan untuk pengujian daya lekat dan lainnya (Rishad, 2016).

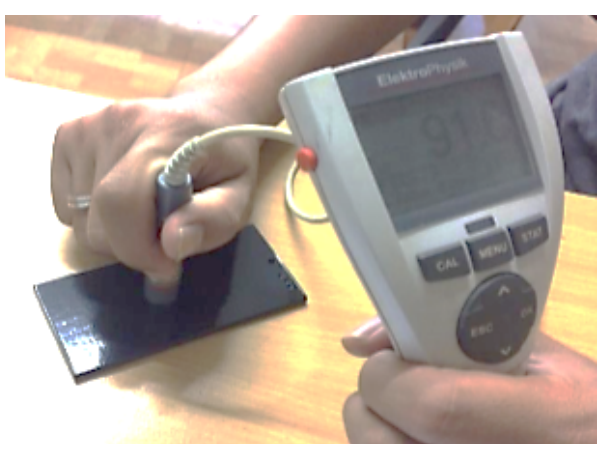

\section{Gambar 4 Coating thickness gauge}

b. Pengujian kerekatan (ASTM D3359).

Coating adhesion bertujuan untuk mengukur tingkat kerekatan cat pada benda kerja logam. Hal ini dimaksudkan untuk mencegah terjadinya pengelupasan pada spesimen yang sudah dicat. Pengujian dilakukan dengan menggunakan metode cross cut, potongan dibuat sampai dasar lapisan cat pada spesimen. Baru direkatkan selotip yang diratakan meng-gunakan penghapus di atas goresan. Selotip diangkat dengan cepat mendekati sudut $90^{\circ}$. Tingkat kerekatan akan diuji dari skala 0-5. (0 berarti lebih dari $65 \%$ area terangkat dan 5 adalah area yang terangkat 0\% (Azis, Moch. Farid, 2017).

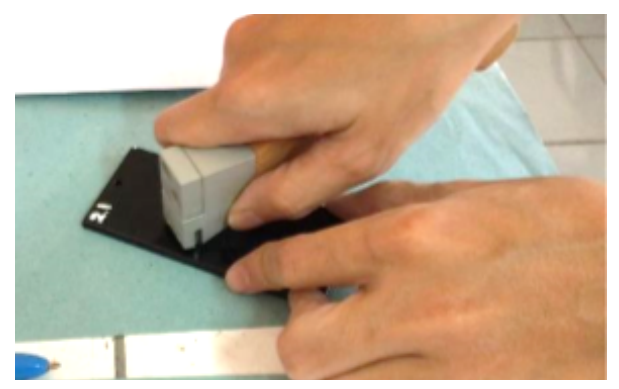

Gambar 5 Cross cut test

c. Pengujian ketahanan (ASTM D2794). Diuji dengan menjatuhkan sebuah impactor dengan berat $18.1 \mathrm{~N}$ dari posisi awal tertinggi dimana lapisan dapat bertahan tanpa rusak oleh impactor. Setelah masing-masing kondisi pelapisan dinilai secara visual, dan jika tidak ada kerusakan mekanik yang ter-lihat, penurunan diulang dari posisi yang lebih tinggi, sampai terjadi kerusakan (Rodger, 2008).

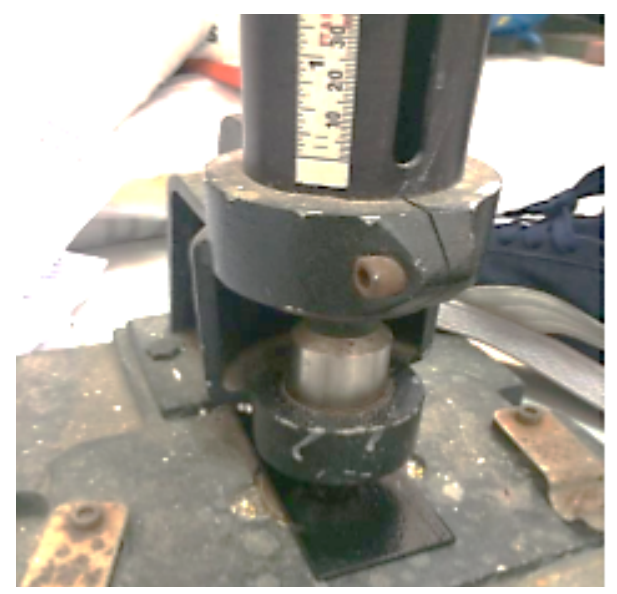

Gambar 6 Impact Test

d. Pengujian daya tarik (ASTM D4541) Pengujian (pull-off test) dilakukan dengan menempelkan dolly pada permukaan lapisan cat, lem pada dolly dikeringkan selama 2 hari, setelah dolly menempel dengan kuat, pada bagian sekeliling dolly di kupas dengan menggunakan dolly cutter sehingga kelihatan permukaan material. Alat elcometer ditempelkan atau memasukkan dolly kedalamnya lalu memutar elcometer hingga dolly terlepas dari permukaan lapisan cat sehingga mendapatkan nilai kekuatan tarik (Maulana, 2015 dan Novi, 2017).

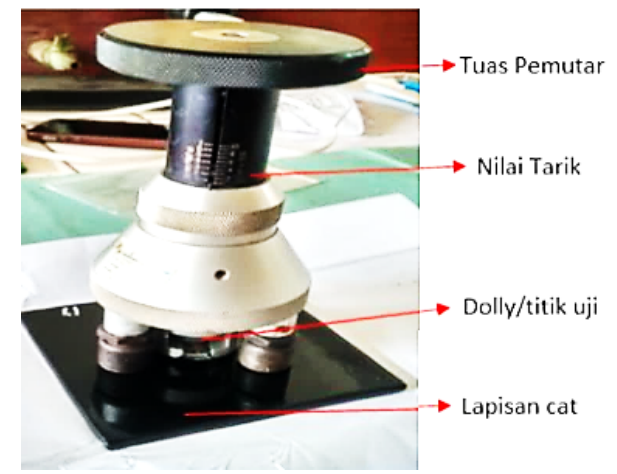

Gambar 7 Pull-Off Test

\section{HASIL DAN PEMBAHASAN}

\section{Hasil Pengujian Visual}

Pengujian visual dilakukan untuk dapat mengetahui hasil coating pada permukaan material yang telah di coating. 

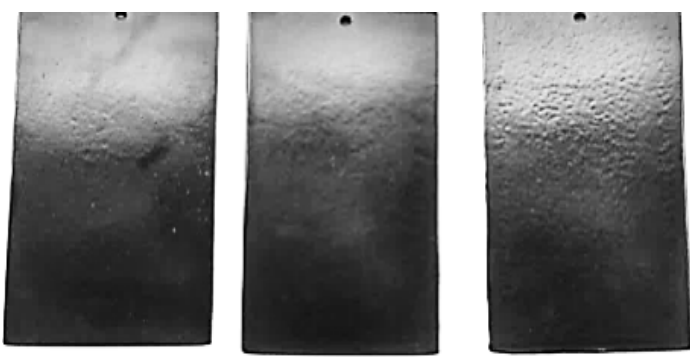

(a) Power tool

(b) Sandblast

(c) Phosphating Gambar 8 Pengecekan visual pretreatment

Hasil pengujian didapatkan hasil sebagai berikut :

a. Phosphating didapatkan hasil coating yang lebih mengikuti tekstur dari permukaan substrat

b. Sandblasting didapatkan permukaan yang bersih dan halus

c. Power tool, terdapat cacat berupa berupa cacat jenis dirt and dust clear coat yang disebabkan oleh kurang bersihnya permukaan dari kotoran.

\section{Hasil Pengujian Ketebalan Lapisan}

Pengujian ketebalan lapisan dilakukan untukmengetahui tebal lapisan yang terdapat pada spesimen dengan menggunakan thickness gauge dengan cara menitikkan thickness gauge pada permukaan spesimen. Hasil pengukuran dapat dilihat pada tabel 1.

Tabel 1 Pengujian ketebalan lapisan

\begin{tabular}{cccc}
\hline \multirow{2}{*}{ No. } & \multicolumn{3}{c}{ Tebal Coating $(\boldsymbol{\mu m})$} \\
\cline { 2 - 4 } & $\begin{array}{c}\text { Power } \\
\text { Tool }\end{array}$ & Sandblasting & Phosphating \\
\hline 1. & 134 & 108 & 95 \\
\hline 2. & 113 & 119 & 130 \\
\hline 3. & 123 & 122 & 110 \\
\hline 4. & 103 & 135 & 107 \\
\hline 5. & 96 & 111 & 101 \\
\hline 6. & 121 & 121 & 89 \\
\hline 7. & 96 & 115 & 108 \\
\hline 8. & 121 & 102 & 105 \\
\hline 9. & 113 & 120 & 107 \\
\hline Rata-rata & 113.3 & 117 & 105.7 \\
\hline
\end{tabular}

Dari hasil pengujian ketebalan lapisan plat dengan thickness gauge ini ketebalan rata-rata lapisan pada power tool $113.3 \mu \mathrm{m}$, sandblasting $117 \mu \mathrm{m}$, phosphating 105.7 $\mu \mathrm{m}$. Ketebalan lapisan yang berbeda-beda ini dikarenakan pada saat proses penyemprotan powder coating dilakukan secara manual sehingga jarak ideal 25-30 cm tidak tercapai.

\section{Hasil Pengujian Kelekatan}

Pengujian kelekatan atau uji adhesion yang dilakuka adalah metode cross cut test.

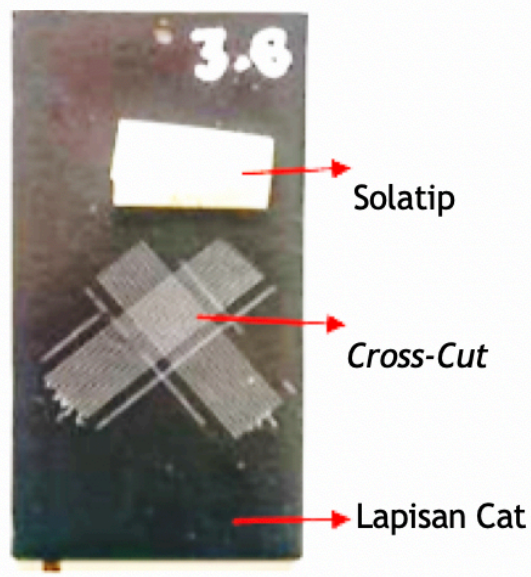

Gambar 9 Uji Cross Cut

Pada pengujian ini lapisan cat digores menyilang dan pada goresan tersebut ditempel dengan solatip. Solatip diangkat dengan cepat mendakati sudut $90^{\circ}$. Hasil pengujian cross-cut dapat dilihat pada tabel 2.

Tabel 2 Hasil Uji Cross Cut

\begin{tabular}{cccc}
\hline \multirow{2}{*}{ No. } & \multicolumn{3}{c}{ \% Terkelupas } \\
\cline { 2 - 4 } & Power Tool & Sandblasting & Phosphating \\
\hline 1. & 0 & 0 & 0 \\
\hline 2. & 0 & 0 & 0 \\
\hline 3. & 0 & 0 & 0 \\
\hline
\end{tabular}

Hasil pengujian adhesion (cross cut test) diatas menunjukan tingkat kelekatan atau adhesi yang sempurna antara coating dan base metal pada seluruh pretreatment. Hasil ini menunjukan bahwa phosphating, sandblasting dan power tool hasil coating tahan terhadap goresan atau tidak mempengaruhi daya lekat coating.

\section{Hasil Pengujian Ketahanan}

Hasil pengujian ketahanan (Impact Test) menunjukkan bahwa setelah setelah pembebanan pada setiap spesimen secara visual ada perubahan fisik pada permukaan film coating berupa adanya retakan dan tidak adanya retakan. Pada pengujian impact dilakukan dengan beban sebesar $18.1 \mathrm{~N}$ dan dijatuhkan pada ketinggian yang bervariasi yaitu $20 \mathrm{~cm}, 40 \mathrm{~cm}$, dan $60 \mathrm{~cm}$. 


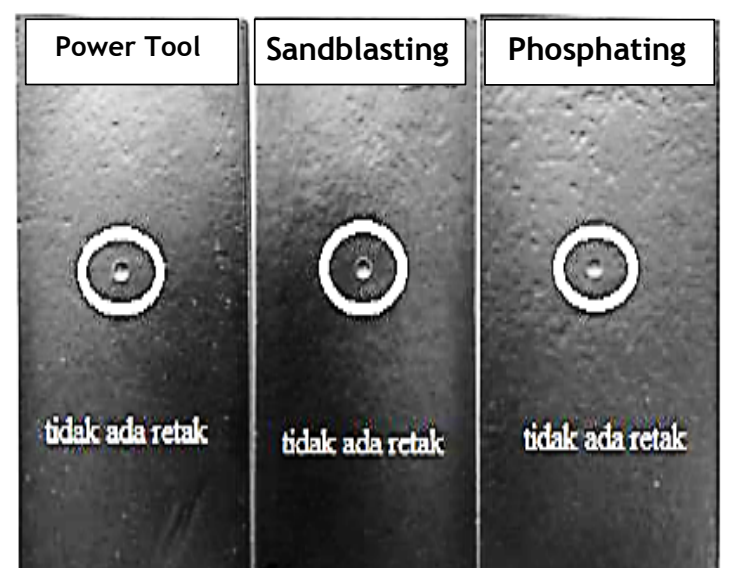

Gambar 10 Hasil uji ketahanan (ketinggian $20 \mathrm{~cm}$ )

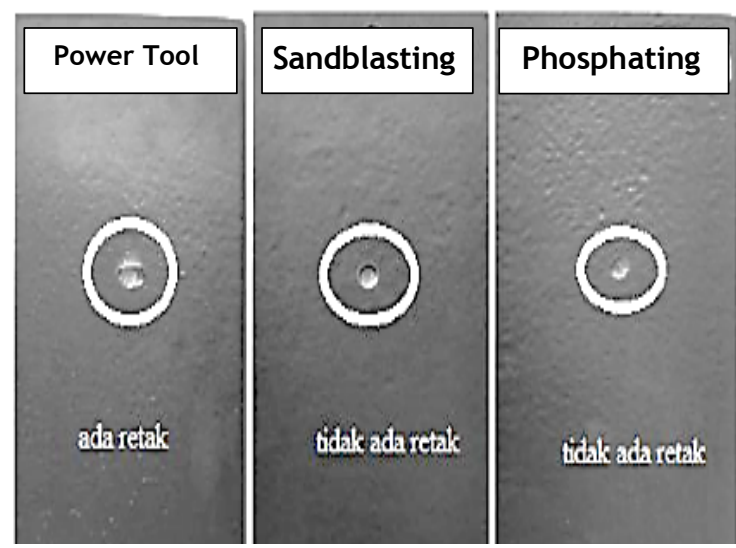

Gambar 11 Hasil uji ketahanan (ketinggian $40 \mathrm{~cm}$ )

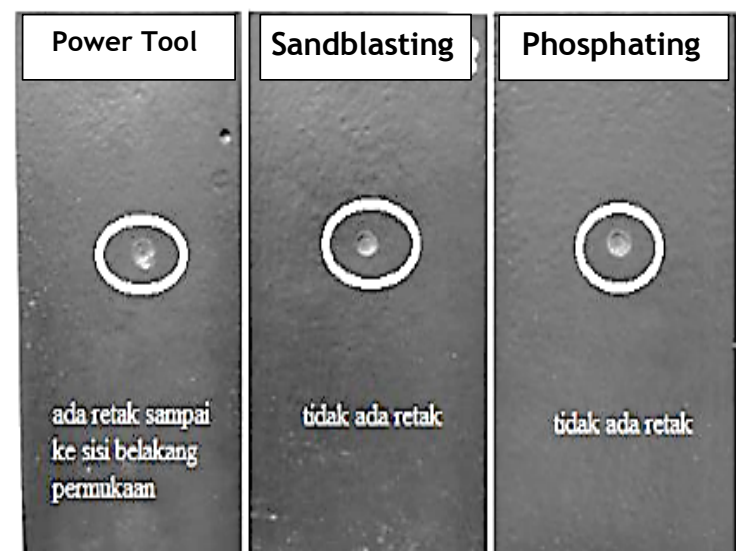

Gambar 12 Hasil uji ketahanan (ketinggian $60 \mathrm{~cm}$ )

Hasil pengujian ketahanan dengan perlakuan awal pada specimen uji dapat dilihat pada tabel 3 berikut.
Tabel 3 Hasil uji ketahanan (Impact Test)

\begin{tabular}{|c|c|c|c|c|}
\hline \multirow{2}{*}{ No. } & \multirow[t]{2}{*}{ Tinggi } & \multicolumn{3}{|c|}{ Ketahanan (Impact) } \\
\hline & & Power Tool & Sandblasting & Phosphating \\
\hline \multirow{2}{*}{1.} & \multirow{2}{*}{$20 \mathrm{~cm}$} & Tidak & Tidak & Tidak \\
\hline & & retak & retak & retak \\
\hline \multirow[b]{2}{*}{2.} & \multirow{2}{*}{$40 \mathrm{~cm}$} & \multirow{2}{*}{ Retak } & Tidak & Tidak \\
\hline & & & retak & retak \\
\hline \multirow[b]{2}{*}{3.} & \multirow{2}{*}{$60 \mathrm{~cm}$} & \multirow{2}{*}{ Retak } & Tidak & Tidak \\
\hline & & & retak & retak \\
\hline
\end{tabular}

Pengujian ketahanan dengan perlakuan awal pada permukaan sampel untuk power tool hasilnya terjadi keretakan pada beban yang dijatuhkan dengan ketinggian $40 \mathrm{~cm}$ dan $60 \mathrm{~cm}$, pada ketinggian $60 \mathrm{~cm}$ keretakan hingga sisi belakang permukaan, sedangkan pada sampel sandblasting dan phosphating tidak menimbulkan retakan. Hal ini menunjukkan daya rekatnya baik.

\section{Hasil Pengujian Daya Rekat}

Hasil pengujian daya rekat (pull-off test) akan menunjukkan nilai tarik pada permukaan lapisan coating.
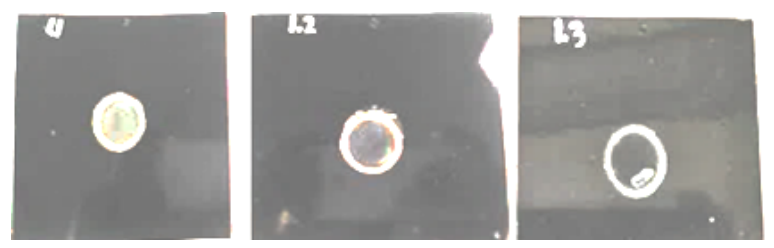

Gambar 13 Hasil uji daya rekat (Power Tool)
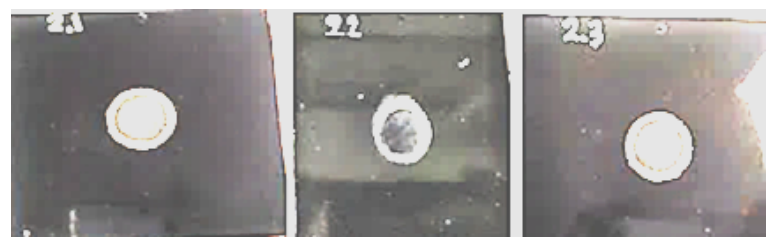

Gambar 14 Hasil uji daya rekat (Sandblasting)
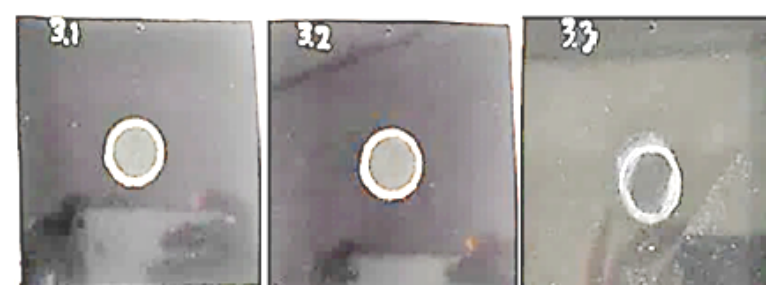

Gambar 15 Hasil uji daya rekat (Phosphating) 
Hasil uji daya rekat dengan perlakuan awal pada specimen uji dapat dilihat pada tabel 4.

Tabel 4 Hasil uji daya rekat (Pull Of Test)

\begin{tabular}{cccc}
\hline & \multicolumn{3}{c}{ Kekuatan Tarik (MPa) } \\
\cline { 2 - 4 } No. & $\begin{array}{c}\text { Power } \\
\text { Tool }\end{array}$ & Sandblasting & Phosphating \\
\hline 1. & 3.5 & 3 & 3.5 \\
\hline 2. & 4 & 3 & 3 \\
\hline 3. & 5 & 3 & 6.5 \\
\hline Rata-rata & 4.17 & 3 & 4.3 \\
\hline
\end{tabular}

Pengujian daya rekat dengan perlakuan awal pada permukaan sampel untuk power tool mempunyai nilai tarik rata-rata 4.17 $\mathrm{MPa}$, pada sandblasting mempunyai nilai rata-rata $3 \mathrm{MPa}$ dan pada phosphating mempunyai nilai rata-rata 4.3 MPa. Hasil ini menunjukan bahwa daya rekat yang mempunyai tertinggi adalah sampel yang mendapatkan perlakuan awal phosphating.

\section{SIMPULAN}

Penelitian proses pengecatan serbuk pada material baja mild steel dengan tiga macam proses perlakuan awal (pretreatment) power tool, sandblasting, phosphating dengan cat bubuk corro-coat MX series 8 (C001) dua layer dapat diambil simpulan bahwa dengan perlakuan awal phosphating didapat hasil terbaik. Hal ini dibuktikan bahwa dengan ketebalan lapisan $105.7 \mu \mathrm{m}$ diperoleh daya rekat tertinggi yaitu nilai tarik rata-ratanya $4.3 \mathrm{MPa}$ serta uji ketahanan tidak ada yang retak.

\section{DAFTAR PUSTAKA}

Azis, Moch. Farid, 2017, Analisa Pengaruh Material Abrasif Pada Proses Blasting Terhadap Kualitas Coating Epoxy, Skripsi, Fakultas Teknologi Kelautan Institut Teknologi Sepuluh Nopember, Surabaya.

Carolus Trijatmiko, Herman Pratikno, dan Agung Purniawan, 2016, Analisa Pengaruh Material Abrasif Pada Blasting Terhadap Kekuatan Lekat Cat dan Ketahanan Korosi di Lingkungan Air Laut,
Jurnal Teknik ITS, Vol. 5, No. 2, pp. G231-G235.

Febi Agusta Ristanto dan Iskandar, 2017, Analisa Pelapisan Powder Coating Pada Box Panel Terhadap Kebocoran Arus Listrik, Jurnal Teknik Mesin, Vol. 05, No. 02 , pp $9-15$

Fontana, Mars Guy, 1986, Corrosion Engineering, Singapore, McGraw-Hill Book Co.

Hudson, R., 1982, Surface Preparation for Coating, The National Physical Labotary.

Karidkar, S. and R. Mali, 2016, Optimization of Powder Spray Process Parameters using Taguchi Methodology, Advances in Intelligent Systems Research, Vol. 137, pp. 71-76.

Maulana Mufti Muhammad, Agung Purniawan dan Hosta Ardhyananta, 2015, Pengaruh Komposisi Pelarut Dan Ketebalan Cat Epoksi Terhadap Daya Lekat Dan Tingkat Pelepuhan Blistering Pada Lingkungan $\mathrm{NaCl}$ Yang Diaplikasikan Pada Baja Karbon, Prosiding Seminar Nasional Material dan Metalurgi (SENAMM VIII), Yogyakarta, 5 November 2015, Departermen Teknik Mesin dan Industri, Universitas Gajah Mada, pp. 144-149.

Novi, Nur Aidha dan Bumiarto Nugroho Jati, 2017, Komparasi Kualitas Cat Alkid Menggunakan Pelarut Hasil Pirolisis Limbah Plastik Polietilen dengan Pelarutdi Industri Cat, Jurnal Kimia dan Kemasan, Vol. 39 No. 2, pp. 87-94.

Rakhmadi, A., 2008, Pengaruh Perlakuan Awal Terhadap Hasil Pelapisan Powder Coating Serta Pengujian Kualitas Dengan Menggunakan Salt Spray Test, Skripsi, Institut Teknologi Sepuluh November, Surabaya

Ramdhoni, Mohammad A, 2015, Pengaruh Variasi Temperatur dan Accelator Asam Nitrit $\left(\mathrm{HNO}_{2}\right)$ Pada Proses Phosphating Diaplikasi Powder Coating Mild Steel ST37, Skripsi, Fakultas Teknik, Universitas Jember, Jember.

Rishad, Antony Pratama dan Sudiyono Kromodiharjo, 2016, Studi Eksperimen Pengaruh Tebal Cat dan Kekasaran pada Pelat Baja Karbon Rendah Terhadap Kerekatan Cat dan Biaya Proses di PT. Swadaya Graha, Jurnal Teknik ITS, Vol. 5, No. 2, pp. F-311- F-315.

Rodger Talbert, 2008, Paint Technology Handbook, CRC Press, New York. 
Yudha Kurniawan Afandi, Irfan Syarif Arief, dan Amiadji, 2015, Analisa Laju Korosi pada Pelat Baja Karbon dengan Varias Ketebalan Coating, Jurnal Teknik ITS, Vol. 4, No. 1, pp G1-G5. 